\title{
OP-0242. IMPROVING GLYCAEMIC CONTROL IN MALAYSIAN PATIENTS WITH TYPE 2 DIABETES WITH INSULIN PUMP THERAPY
}

Noor Rafhati Adyani Abdullah,Azraai Bahari Nasruddin,Masni Muhammad,Nurain Mohd Noor,Zanariah Hussein Diabetes and Endocrinology Unit, Department of Medicine, Putrajaya Hospital, Malaysia

\section{Introduction}

- Type 2 diabetes is a progressive disease, characterized by ongoing decline in beta cell function. In advanced disease, many patients develop worsening diabetes control, and ultimately require insulin.

- In addition, a growing number of insulin-treated patients require high doses of insulin.

- Opt2mise study demonstrated the efficacy of insulin pump therapy in long standing poorly controlled type 2 diabetes on multiple daily injections. ${ }^{1}$

- In Malaysia, approximately $30 \%$ of insulin users were on premixed insulin regimen due to the cost and presumed convenience. ${ }^{2}$ Those patients who fail premixed insulin are usually intensified with multiple daily injections of insulin.

\section{Aim}

- To evaluate the comparative efficacy of insulin pump therapy versus multiple daily injections in insulin resistant type 2 DM patients who are sub-optimally controlled with premixed insulin regimen.

\section{Methodology}

Study design (Figure 1)

- 12 - months randomized, parallel-group, open-label trial with a single-arm cross-over in the continuation phase

- Participants were recruited from the Endocrine clinics and General Medical outpatient clinics, Putrajaya Hospital since January 2016.

- The participants were insulin-taking patients who were sub optimally controlled on premixed insulin regimen twice or three times daily (defined as having an $\mathrm{HbA} 1 \mathrm{c}>8 \%$ ).

- The participants entered an 8-week dose optimisation run-in period and at the end of the run-in period, insulin dosage was at minimum $1.0 \mathrm{U} / \mathrm{kg} /$ day and at maximum $1.7 \mathrm{U} / \mathrm{kg} /$ day, or a maximum of $200 \mathrm{U} /$ day.

- This was followed by randomisation into two interventional arms which were CSII and MDI. After 6 months, the participants on the MDI arm crossed over to CSII for another 6 months. Neither patients nor investigators were masked to treatment allocation.

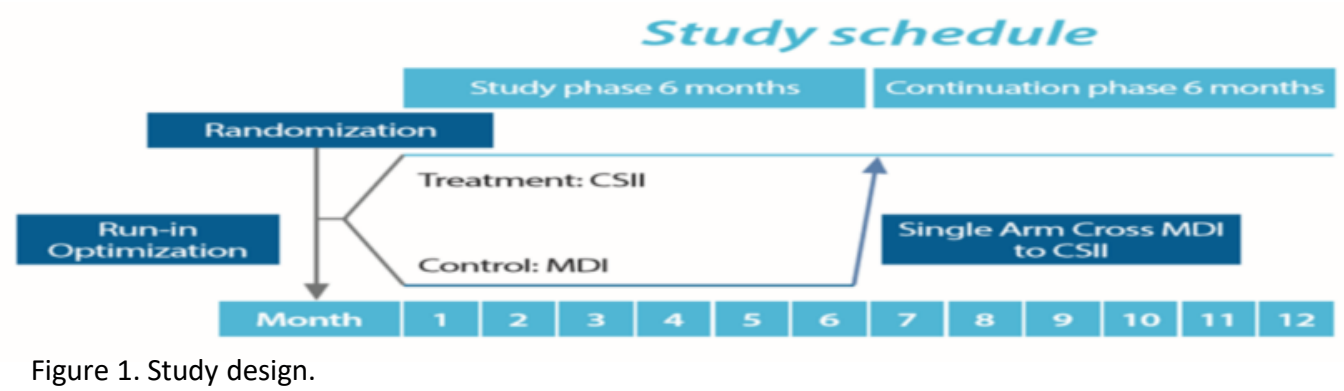

Endpoints

- Primary endpoint : change in mean glycated haemoglobin between baseline and 6 months

- Secondary endpoints : safety, metabolic profiles, total insulin dosage, within group difference in $\mathrm{HbA} 1 \mathrm{c}$ from 6 months to 12 months and the number of self-monitoring blood glucose(SMBG)/day.

\section{Results}

- These results were the interim analysis for the first 6 months.

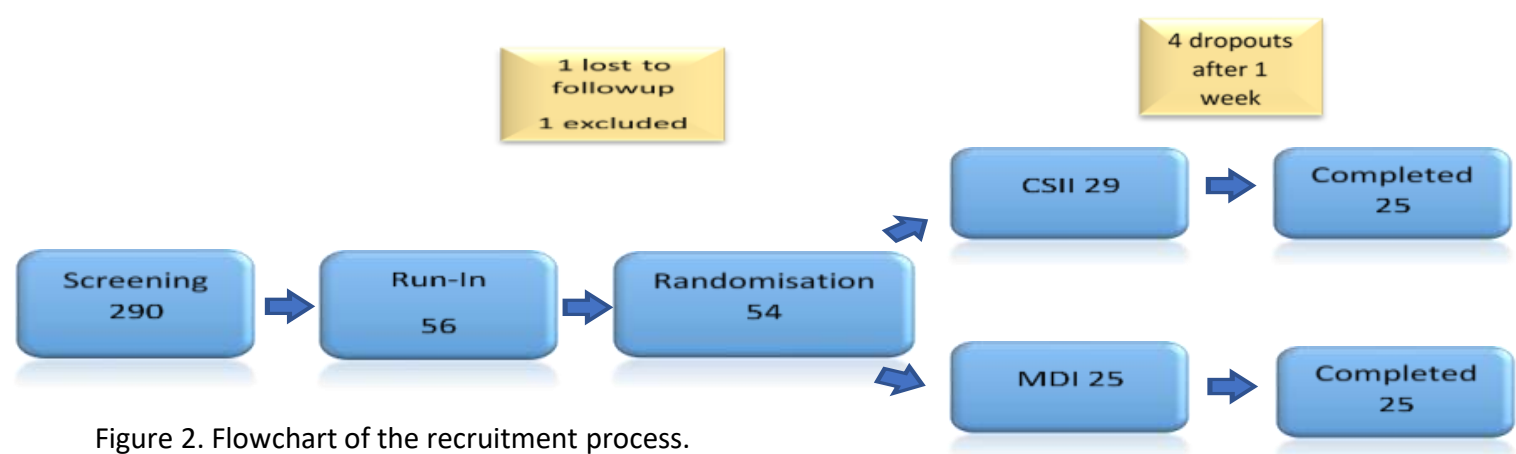

Acknowledgements

The study was sponsored by Medtronic. The insulin was funded by MEMS, CRC HPJ,NIH and Novo Nordisk.
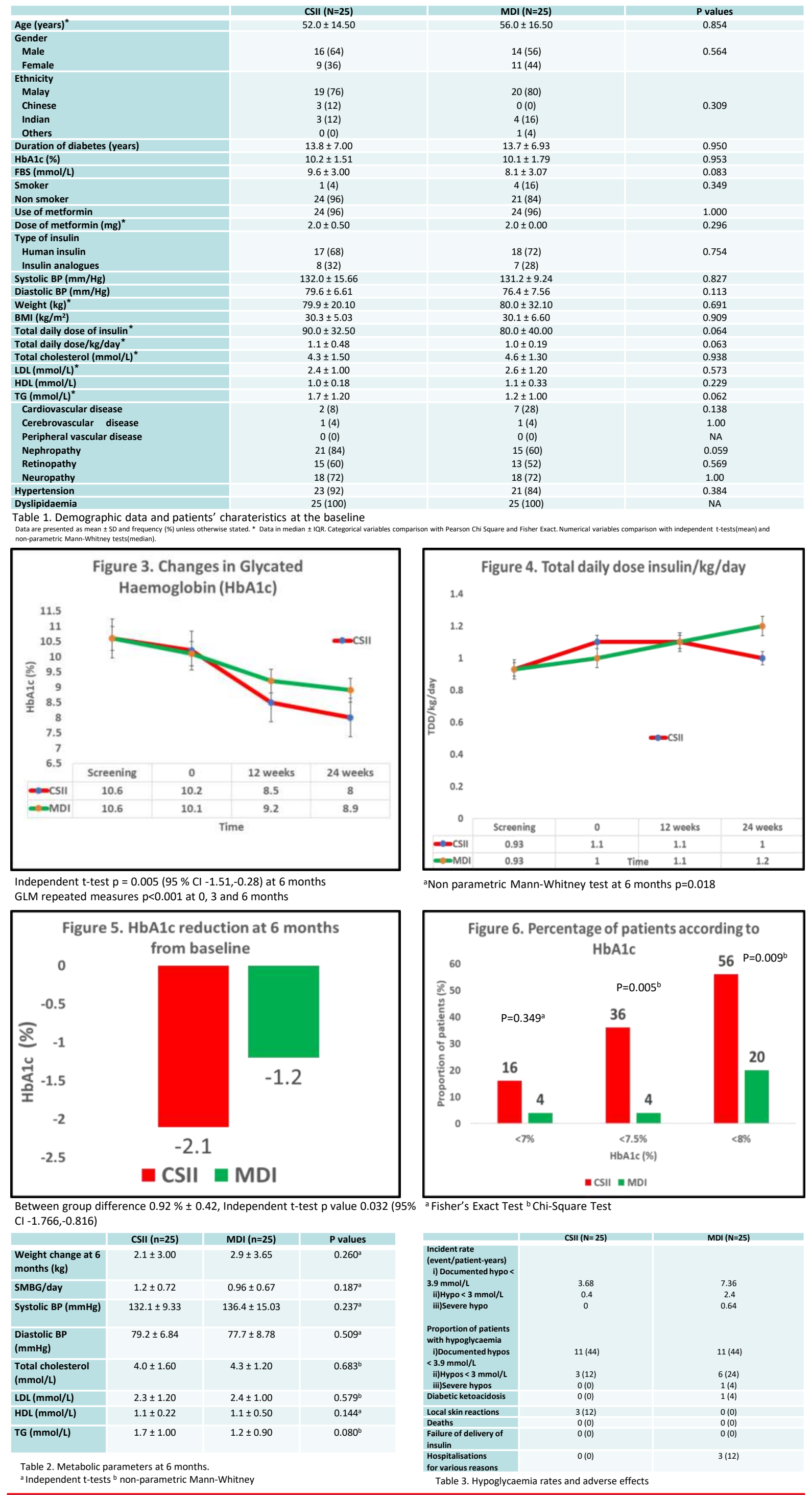

Discussion

- Improvements in HbA1c were achieved in both groups, but with greater improvement observed with pump therapy.

- Potential explanations include:

1)a more physiological method of delivery

2)Improved absorption of smaller subcutaneous insulin depots with continuous insulin infusion

3)Prevention of the hyperglycaemia of the dawn phenomenon 4)Prevention of hypoglycaemia that becomes a barrier to insulin intensification

5)improved adherence to insulin dosing

- The improvement in HbA1c was observed with significantly reduced insulin requirement and less hypoglycaemia events.

\section{Conclusion}

- Insulin pump therapy is effective and safe for insulin resistant type 2 DM patients who have been on intensified premixed insulin and remained far from achieving target glycaemic control.

References

Reznik Y, Cohen O, Aronson R, Conget I, Runzis S, Castaneda J, et al. Insulin pump treatment compared with multiple daily injections for treatment of type 2 diabetes (OpT2mise): a randomised open-labe

Mafauzy Mohamed, Zanariah Hussein, Avideh Nazeri, Siew Pheng Chan. DiabCare 2013: A cross-sectional study of hospital based diabetes care delivery and prevention of diabetes related complications in Malaysia. Med J Malaysia. 2016; 71(4):177-185 